\title{
Cardiovascular adverse events in multiple myeloma patients
}

\author{
Markus B. Heckmann ${ }^{1,2}$, Shirin Doroudgar ${ }^{1,2}$, Hugo A. Katus ${ }^{1,2}$, Lorenz H. Lehmann ${ }^{1,2}$ \\ ${ }^{1}$ Department of Cardiology, Angiology, and Pneumology, Internal Medicine III, University Hospital Heidelberg, 69120 Heidelberg, Germany; \\ ${ }^{2}$ DZHK (German Centre for Cardiovascular Research), Partner Site Heidelberg/Mannheim, 69120 Heidelberg, Germany \\ Contributions: (I) Conception and design: All authors; (II) Administrative support: None; (III) Provision of study materials or patients: None; (IV) \\ Collection and assembly of data: All authors; (V) Data analysis and interpretation: All authors; (VI) Manuscript writing: All authors; (VII) Final \\ approval of manuscript: All authors. \\ Correspondence to: Dr. med. Lorenz H. Lehmann. Department of Cardiology, Angiology, and Pneumology, Heidelberg University Hospital, INF 410, \\ 69120 Heidelberg, Germany. Email: lorenz.lehmann@med.uni-heidelberg.de.
}

\begin{abstract}
Multiple myeloma is a malignant disease, caused by an uncontrolled clonal proliferation of a specific group of white blood cells, the plasma cells. Clinical manifestations include bone pain due to osteolysis, hypercalcemia, anemia, and renal insufficiency. Proteasome inhibitors have substantially improved survival of patients suffering from multiple myeloma, providing an efficient treatment option mainly for relapsed and refractory multiple myeloma. Although constituting one substance class, bortezomib, carfilzomib, and ixazomib differ greatly regarding their non-hematologic side effects. This article reviews the clinical and preclinical data on approved proteasome inhibitors in an attempt to decipher the underlying pathomechanisms related to cardiovascular adverse events seen in clinical trials.
\end{abstract}

Keywords: Multiple myeloma; cardio-oncology; cardiotoxicity; proteasome inhibitors; carfilzomib; bortezomib; ixazomib

Submitted Sep 03, 2018. Accepted for publication Sep 18, 2018.

doi: $10.21037 /$ jtd.2018.09.87

View this article at: http://dx.doi.org/10.21037/jtd.2018.09.87

\section{Introduction}

Multiple myeloma is caused by an uncontrolled clonal proliferation of a specific group of white blood cells, the plasma cells. Worldwide the incidence rate of multiple myeloma is 2.1 per 100,000 persons. The highest incidence was reported in high-income North-America and Western Europe with 5.2/100,000 persons and 4.6/100,000 persons, respectively. The disease accounted for 2.1 million disability adjusted life years globally in 2016 (1).

Clinical manifestations include bone pain due to osteolysis, hypercalcemia, anemia, and renal insufficiency. Disease-related and therapy-related adverse cardiovascular events demand close interdisciplinary collaboration between cardiologists and oncologists to ensure optimal medical care. Changes in plasma composition and baseline therapy increase the thromboembolic risk to $1-2 \%$ (2). The risk might further increase up to $25 \%$ depending on the chemotherapeutic/immune agents used (2). Furthermore, uncontrolled immunoglobulin light-chain production seen in some patients is related to the development of cardiac amyloidosis as a severe complication (3). As multiple myeloma is frequently incurable, its therapy aims at improving overall survival and patients' quality of life. Recent advances in the treatment of refractory stages, including the introduction of modern immunomodulatory drugs and proteasome inhibitors, have increased overall survival tremendously (4). While immunomodulatory drugs such as lenalidomide have been associated with an increase of thromboembolic events, proteasome inhibitors such as carfilzomib have been associated with an increase in heart failure and arrhythmias $(2,4)$.

The following review aims to give an overview of the current literature about therapy-related cardiac events in patients with multiple myeloma. Especially, the last generation of proteasome inhibitors with its most prominent agent "carfilzomib", has been related to a significant number of cardiac events. Protein quality 
control, with which proteasome inhibitors mostly interfere, is an essential part of the molecular machinery of cardiomyocytes, endothelial cells, and presumably all other members of the cardiac environment. Therefore, the second part of the review will give mechanistic insights on the role of the ubiquitin-proteasome pathway in cardiomyocytes with potential cardioprotective targets.

\section{What can we learn from clinical data?}

The first proteasome inhibitor approved for the treatment of multiple myeloma was bortezomib. Relying on data of the phase II SUMMIT trial, FDA (US Food and Drug Administration) approval was granted in 2003 (5). Partially reversible neurotoxicity was reported as the main nonhematologic side effect $(6,7)$. Interestingly, cardiovascular events were not closely monitored and not well reported in clinical trials investigating the effects of bortezomib. The Assessment of Proteasome inhibition for Extending Remission (APEX) trial was the first to monitor cardiac events. In this study, similar event rates in the bortezomib and non-bortezomib group were reported (6).

Significantly improved overall response rates, even when compared to bortezomib, lead to FDA and European Medicines Agency (EMA) approval of carfilzomib in 2012 and 2016, respectively $(8,9)$. An increase in hypertension, heart failure, and ischemic heart disease in the carfilzomib arm of the ASPIRE trial (Carfilzomib, Lenalidomide, and Dexamethasone versus Lenalidomide and Dexamethasone for the Treatment of Patients with Relapsed Multiple Myeloma; see Table 1) led to the post-marketing requirement to conduct another trial including a subgroup that was closely monitored for significant changes in cardiac function (see FDA Application No. 202714Orig1s000 PMR 1908-2) (8). The ENDEAVOR trial evaluated the efficacy and safety of carfilzomib (464 enrolled patients) in a direct comparison to bortezomib (465 patients). Response rates as well as cardiac side effects (hypertension and heart failure) were significantly higher in the carfilzomib arm, while neurotoxic side effects were more frequently observed under bortezomib treatment (9). In the interpretation of cardiac events in ENDEAVOR, there are some limitations: Only clinically overt heart failure was reported, cardiac biomarkers were not consequently measured, changes in left ventricular function were only sequentially measured in a subpopulation, and not reported in discrete data (9). However, when compared to other randomized controlled trials investigating the effects of proteasome inhibitors in patients suffering from multiple myeloma, ENDEAVOR gives the most detailed report on cardiac side effects (see Table 1). Patients with a left ventricular ejection fraction $<40 \%$ or clinical symptoms of heart failure (NYHA III or NYHA IV) or recent history of myocardial infarction or symptoms of cardiac ischemia were excluded from the trial.

Ultimately, ixazomib, an orally administered proteasome inhibitor, was approved for the treatment of relapsed and refractory multiple myeloma by the FDA and EMA in 2015 . In the largest trial, which randomized ixazomib $v s$. placebo on top of lenalidomide and dexamethasone, gastrointestinal side effects were the most prominent non-hematologic adverse events associated with ixazomib (15). The incidence of hypertension $(6 \%$ in the placebo $v s .5 \%$ in the ixazomib group), heart failure ( $4 \%$ in both arms), arrhythmia (16\% in placebo $v s .15 \%$ in the ixazomib group), and myocardial infarction ( $1 \%$ vs. $2 \%$ ) differed not significantly, suggesting less cardiotoxicity. Mechanistically, ixazomib inhibits the proteasome activity reversibly, comparable to the mode of action of bortezomib. Patients with clinical symptoms of arrhythmias, heart failure, or unstable angina were excluded from the trial. Venous thromboembolism was less frequent ( $8 \%$ vs. $11 \%$ ) with the addition of ixazomib (15). Venous thromboembolism was also unexpectedly low in patients treated with bortezomib in combination with lenalidomide and dexamethasone (12).

Further proteasome inhibitors, currently not approved by the FDA or EMA, have been tested with varying results. Delanzomib and oprozomib did show only limited activity against multiple myeloma. Most frequently occurring nonhematologic adverse events were minor neuropathies and gastrointestinal side effects, respectively $(16,17)$. Marizomib, an irreversible proteasome inhibitor, showed promising results regarding anti-tumor activity. Cardiac side effects were not reported so far. Also, parameters indicative of cardiac side effects, such as left ventricular ejection fraction, longitudinal strain, or biomarkers, however, were not reported/measured (18). Some recent studies only report or measure electrocardiogram (ECG) data (16). However, ECG screening is not sufficient to detect cardiotoxicity and did not reveal the inherent cardiotoxicity of carfilzomib (13).

Interestingly, Clinical data also show that proteasome inhibitors might be protective against venous thromboembolism in patients at increased risk. Patients treated with lenalidomide (immunomodulatory drugs) and dexamethasone had less thromboembolic events with the addition of a proteasome inhibitor (11\% without ixazomib vs. $8 \%$ with ixazomib, see Table 1) (15). Another phase I 
Table 1 Selected published clinical trials on EMA and FDA approved proteasome inhibitors in multiple myeloma

\begin{tabular}{|c|c|c|c|c|c|c|c|c|}
\hline $\begin{array}{l}\text { Proteasome } \\
\text { inhibitor }\end{array}$ & Acronym & Phase & No. subjects & Clinical setting & Treatment & ORR & $\begin{array}{l}\text { Cardiovascular } \\
\text { adverse events }\end{array}$ & Ref. \\
\hline Bortezomib & Summit & II & 196 & Relapsed MM & BTZ & $35 \%$ & $\begin{array}{l}\text { Not reported/ } \\
\text { measured }\end{array}$ & (5) \\
\hline Bortezomib & APEX & III & 669 & Relapsed MM & BTZ vs. Dexa & $\begin{array}{l}38 \% \text { vs. } \\
18 \%\end{array}$ & $\begin{array}{l}\text { Cardiac events } 15 \% \\
\text { vs. } 13 \% \text {; heart failure } \\
2 \% \text { in both groups }\end{array}$ & (6) \\
\hline Bortezomib & $\begin{array}{l}\text { HOVON-65/ } \\
\text { GMMG-HD4 }\end{array}$ & III & 827 & $\begin{array}{l}\text { Newly } \\
\text { diagnosed MM }\end{array}$ & $\begin{array}{l}\text { BTZ + Doxo + Dexa } \\
\text { vs. Vinc + Doxo + } \\
\text { Dexa }\end{array}$ & $\begin{array}{l}36 \% \text { vs. } \\
24 \%\end{array}$ & $\begin{array}{l}\text { Not reported/ } \\
\text { measured }\end{array}$ & (11) \\
\hline Carfilzomib & - & II & 50 & $\begin{array}{l}\text { Relapsed/ } \\
\text { refractory MM }\end{array}$ & CFZ & $26 \%$ & $\begin{array}{l}\text { Congestive heart } \\
\text { failure } 6 \% \text {; no notable } \\
\text { changes on ECG }\end{array}$ & (13) \\
\hline Carfilzomib & ASPIRE & III & 792 & Relapsed MM & $\begin{array}{l}\text { CFZ + Len + Dexa } \\
\text { vs. Len + Dexa }\end{array}$ & $\begin{array}{l}87 \% \text { vs. } \\
67 \%\end{array}$ & $\begin{array}{l}\text { Hypertension } 14.3 \% \\
\text { vs. } 6.9 \% \text {; cardiac } \\
\text { failure } 6.4 \% \text { vs. } \\
4.1 \% \text {; ischemic heart } \\
\text { disease } 5.9 \% \text { vs. } \\
4.6 \%\end{array}$ & (8) \\
\hline Carfilzomib & FOCUS & III & 315 & $\begin{array}{l}\text { Relapsed/ } \\
\text { refractory MM }\end{array}$ & $\begin{array}{l}\text { CFZ vs. } \\
\text { corticosteroids }\end{array}$ & $\begin{array}{l}19 \% \text { vs. } \\
11 \%\end{array}$ & $\begin{array}{l}\text { Hypertension } 15 \% \text { vs. } \\
6 \% \text {; cardiac failure } \\
5 \% \text { vs. } 1 \%\end{array}$ & (14) \\
\hline Ixazomib & $\begin{array}{l}\text { TOURMALINE- } \\
\text { MM1 }\end{array}$ & III & 722 & $\begin{array}{l}\text { Relapsed/ } \\
\text { refractory MM }\end{array}$ & $\begin{array}{l}\text { IXZ + Len + Dexa } \\
\text { vs. Len + Dexa }\end{array}$ & $\begin{array}{l}78 \% \text { vs. } \\
72 \%\end{array}$ & $\begin{array}{l}\text { Hypertension } 6 \% \\
\text { vs. } 5 \% \text {; hypotension } \\
6 \% \text { vs. } 6 \% \text {; venous } \\
\text { thromboembolism } \\
8 \% \text { vs. } 11 \% \text {; heart } \\
\text { failure } 4 \% \text { vs. } 4 \% \text {; } \\
\text { arrhythmia } 16 \% \text { vs. } \\
15 \% \text {; myocardial } \\
\text { infarction } 1 \% \text { vs. } 2 \%\end{array}$ & (15) \\
\hline
\end{tabular}

MM, multiple myeloma; BTZ, bortezomib; Dexa, dexamethasone; TH, thalidomide; Vinc, vincristine; Doxo, doxorubicin; Len, lenalidomide; CFZ, carfilzomib; IXZ, ixazomib; ORR, overall response rate; EMA, European Medicines Agency; FDA, Food and Drug Administration. 
trial on bortezomib in combination with lenalidomide and dexamethasone only showed a venous thromboembolism rate of $3 \%$, which is strikingly low when compared to lenalidomide and dexamethasone therapy in other studies without proteasome inhibitors (12). Different proteasome inhibitors exhibit distinct non-hematologic side effects. Simplified, with all limitation of the current literature, we can conclude, that bortezomib is mainly associated with neurotoxicity, ixazomib with gastrointestinal side effects, and carfilzomib with cardiotoxicity.

According to a pooled analysis of phase II studies on carfilzomib comprising 526 patients, $22 \%(\mathrm{n}=116)$ of patients developed cardiac side effects, $13.3 \%(n=70)$ showed arrhythmia, mainly atrial fibrillation, 7.2\% ( $\mathrm{n}=38)$ exhibited heart failure, $2 \%(\mathrm{n}=9)$ developed treatmentassociated cardiomyopathy, and 3\% $(n=18)$ suffered from ischemic heart disease. Most cardiovascular events occurred early with the first few doses administered (19). A recent retrospective study on 96 patients with multiple myeloma treated with bortezomib or carfilzomib, which sought to identify patients at risk for proteasome inhibitorrelated cardiotoxicity, was not able to show any classic cardiovascular risk factor (e.g., hypertension, smoking, diabetes, etc.) to be predictive. History of atrial fibrillation/ flutter or heart failure, however, was significantly more prevalent in patients experiencing cardiovascular events, emphasizing the importance of closely monitoring patients under proteasome inhibitor use (20). Concomitant radiation of the chest and anthracycline therapy increases the risk for carfilzomib mediated cardiotoxicity, while baseline biomarkers and echocardiography were not able to identify patients at an increased risk for cardiovascular events $(21,22)$. Serum troponin levels are not indicative of heart failure. However, nt-pro-BNP levels concomitantly rise with decreased ejection fraction (23). Thus, clinical follow up with echocardiography and biomarkers is controversially discussed.

\section{What can we learn from preclinical data?}

The proteasome is an essential cellular component, responsible for the recycling of intracellular proteins. Proteasomes are protein complexes responsible for the elimination of misfolded proteins but also a major mechanism by which cells regulate the balance of protein generation and elimination (24). Proteasomes are widely distributed in the cytosol and in the nucleus of all eukaryotic cells. In the cytosol, proteasomes associate with the centrosomes, the cytoskeleton, and the outer surface of the endoplasmic reticulum. In the nucleus, proteasomes are present throughout the nucleoplasm except for in the nucleoli $(25,26)$. The ubiquitin-proteasome system (UPS) is the main protein degradation system in the heart (27). As much as $30 \%$ of newly synthesized proteins are terminally misfolded and therefore degraded by the proteasome shortly after their synthesis (28). Moreover, the UPS allows cells to adapt to changing physiological conditions by controlling the proteins that are in turn responsible for protein expression in response to stress. The UPS is also important for the maintenance of protein turnover of obsolete, oxidized, mutant, denatured, and misfolded proteins (29). Defects in UPS have been linked to cardiovascular disease, including atherosclerosis, familial and idiopathic cardiomyopathies, myocardial ischemia, hypertrophy, reperfusion injury, and heart failure (30-34). Under physiological conditions, the proteasome activity is the highest in cardiac and renal tissue (35). This is not surprising, because non-proliferating cells tightly control their protein turnover for adaptive and maladaptive remodeling.

The proteasome complex consists of more than 45 subunits that are divided into core particles and regulatory particles. Bortezomib, carfilzomib, and ixazomib target the 20S constitutive proteasome, which consists of four heptameric rings: two external alpha rings, which regulate the entrance of protein, and two internal beta rings that contain protease active sites. Proteasome inhibitors mainly target the $\beta 1, \beta 2$, and $\beta 5$ subunits of the internal ring (36). The constitutive proteasome is present in all cells. In lymphocytes and monocytes, IFN- $\gamma$ and TNF- $\alpha$ stimulation leads to the formation of immunoproteasomes, in which the subunits $\beta 1 \mathrm{c}, \beta 2 \mathrm{c}$, and $\beta 5 \mathrm{c}$ are replaced by $\beta 1 \mathrm{i}, \beta 2 \mathrm{i}$, and $\beta 5 \mathrm{i}$ (see Figure 1) (36). All currentlyapproved proteasome inhibitors are targeting both, the immunoproteasome and the constitutive proteasome, in which carfilzomib more selectively and irreversibly binds to the $\beta 5$ subunit and bortezomib binds reversibly to the $\beta 1$ and $\beta 5$ subunits $(24,36)$.

Interestingly, carfilzomib does also accumulate in the heart and leads to a strong inhibition of the cardiac proteasome as shown in the initial FDA-approval data. Moreover, the inhibition is stronger as in the targeted bone marrow cells. Carfilzomib reduces the 20S chymotrypsinlike activity down to $10 \%$ in cardiac cells and down to $45 \%$ in bone marrow cells 5 minutes after administration. A dose-dependent inhibition was found down to $28-56 \% 24$ 


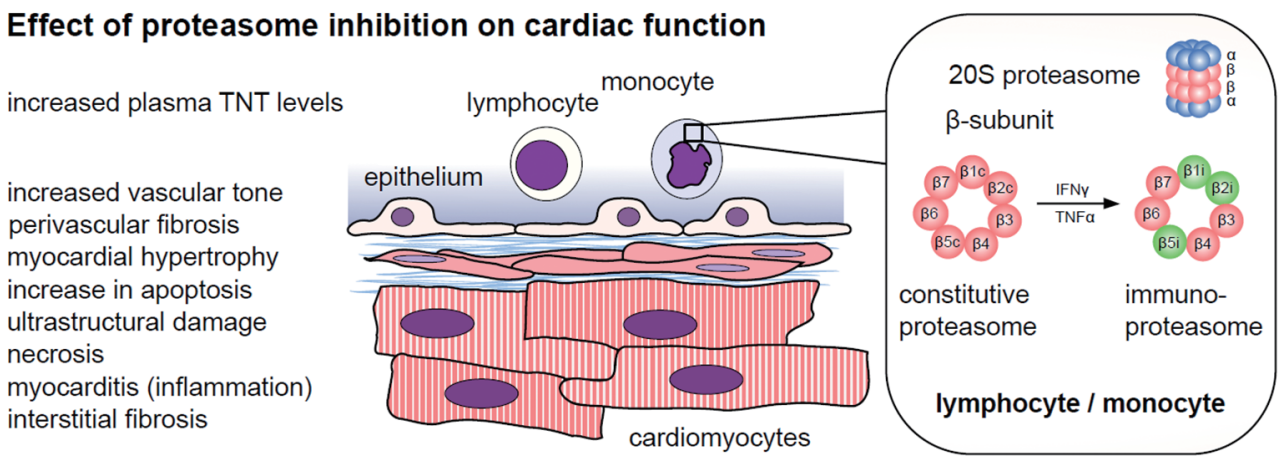

Figure 1 Effect of proteasome inhibition on cardiac function. Pathologic alterations, associated with carfilzomib administration (left-hand side), scheme of the involved compartments (middle), scheme of the $20 \mathrm{~S}$ proteasome (right-hand side), with the differences between the constitutive proteasome and the immunoproteasome found in TNF- $\alpha$ or IFN- $\gamma$ activated lymphocytes and monocytes as indicated.

$\mathrm{h}$ after last treatment with complete recovery after 28 days in cynomolgus monkeys [see studies TR-0018-171/TXC004/TR-0011-171/TXC-003/TR-0046-171-PD in FDA: 202714Orig1s000 PHARMACOLOGY REVIEW(s)]. In rats, treatment with carfilzomib led to a reduction of the cardiac chymotrypsin-like activity down to $50 \% 24 \mathrm{~h}$ after treatment, compared to a reduction down to $80 \%$ in the bortezomib group (37). Monkeys treated with repeated doses of carfilzomib above $1 \mathrm{mg}$ per $\mathrm{kg}$ body weight developed hypotension, increased serum troponin $\mathrm{T}$ levels, and increased heart rates. Histopathologic analyses showed inflammation, myocyte hypertrophy, and myocardial degeneration [see FDA: 202714Orig1s000 MEDICAL REVIEW(s) Section 4.3]. One could argue, that an increase of cardiotoxic events would be quite expected based on these preclinical data.

Currently, there is a strong effort to decipher the underlying molecular mechanisms of the observed clinical effects. Therapeutic dosages lead to endothelial dysfunction, myocardial hypertrophy, myocarditis, increase in apoptosis, necrosis, and ultrastructural damage in preclinical models (see Figure 1) (38).

Endothelial dysfunction following carfilzomib treatment leads to an increase in vascular tone and vasospasms, which are only partially reversed by the application of nitrates and calcium-antagonists. These effects might explain hypertension, the most frequent cardiovascular side effect, and maybe to some extent the nominal increase in myocardial infarction $(38,39)$. The above mentioned thrombo-protective effects of bortezomib, and presumably carfilzomib, in combination with immune-modulatory drugs is mediated by an increased expression of Kruppel- like factor 2 (KLF2) (40).

Irreversible inhibition of the $20 \mathrm{~S}$ proteasome by carfilzomib leads to an imbalance of ubiquitylated and non-ubiquitylated proteins, altering protein function and cell signaling (41). An increase of ubiquitylated major vault proteins and heat shock proteins due to proteasome inhibition has been associated with increased left ventricular apoptosis (42). While low dose bortezomib lead to a downregulation of Akt, Erk1/2, and calcineurin, which implies a cardioprotective and anti-hypertrophic effect, therapeutic dosages lead to mitochondrial dysfunction, a decrease in ATP synthesis, disturbed $\mathrm{Ca}^{2+}$-handling, and ultimately cardiac dysfunction $(43,44)$. Direct cardioprotective effects of carfilzomib have not been described. Carfilzomib treatment led to a number of intracellular events, such as activation of NF- $\kappa B$, ERK and JNK, with a subsequent increase in hypertrophic gene expression, increase in caspase-3 activity, p65, and increase in reactive oxygen species (ROS), and a decrease in I $\kappa \alpha$, an inhibitor of NF- $\mathrm{KB}$ (45-47). According to the activation of pro-hypertrophic MAP-kinases, proteasome inhibition does also activate the NFAT-calcineurin pathway, a classical prohypertrophic pathway in cardiomyocytes (48). Activation of the intracellular pro-hypertrophic programs is currently understood as an initial event of pathological cardiac remodeling, followed by apoptosis, fibrosis, and cardiac dysfunction. Further synergistic cardiotoxic effects of proteasome inhibitors and anthracyclines can be explained by an additional generation of ROS (49). To sum up, proteasome inhibitors, administered at therapeutic dosages lead to an increase in ubiquitylated proteins, indicating intracellular accumulation of misfolded, potentially toxic 


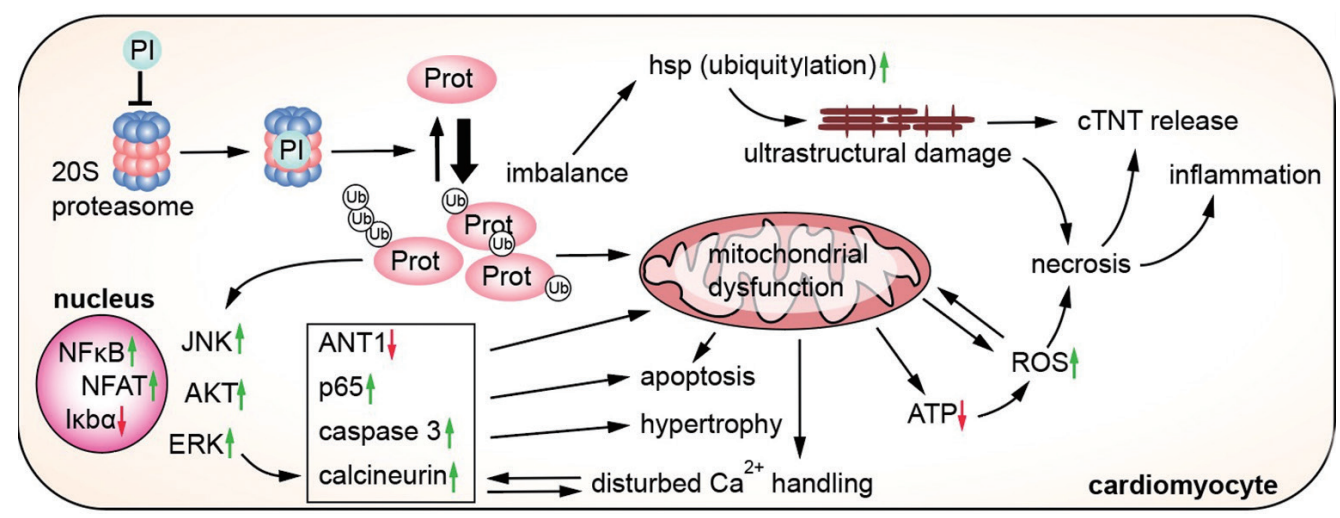

Figure 2 Overview of the involved cardiotoxic pathomechanisms of proteasome inhibitors based on Table 2. PI, protein inhibitor; Prot, protein; Ub, ubiquitin; JNK, c-Jun N-terminal kinase; NF- $\kappa \mathrm{B}$, nuclear factor kappa-light-chain-enhancer of activated B cells; NFAT, nuclear factor of activated T-cells; ERK, extracellular signal-regulated kinase; ANT1, adenine nucleotide translocator 1; p65, transcription factor p65; Iкb $\alpha$, inhibitory kappa B-alpha; hsp, heat shock proteins; cTNT, cardiac troponin T; ROS, reactive oxygen species; ATP, adenosine triphosphate.

proteins, as well as activation of Akt, $\mathrm{NF}-\kappa \mathrm{B}$, and the NFAT-calcineurin pathways, which lead to myocardial hypertrophy. NF- $\kappa \mathrm{B}$ activation, decreasing ANT1 (adenine nucleotide translocase type 1) expression, and the burden of intracellular, ubiquitylated proteins further affect intracellular signaling and induce mitochondrial dysfunction, ROS production, and ultrastructural changes. Subsequently, this leads to an increase of apoptosis, necrosis, and release of cardiac troponin (see Figure 2) $(41,50)$.

Cardioprotective strategies that have been successfully tested in preclinical studies include the co-administration of dexrazoxane, whereas the underlying mechanism of the protective effect of this chelator is not fully understood. Rutin, a NO scavenger, counteracts increased ROS production; apremilast, a phosphodiesterase 4 inhibitor decreases TNF- $\alpha$ secretion. Another strategy consists of selectively targeting the immunoproteasome $(42,45$ 47,49). Table 2 provides an overview of preclinical studies investigating the cardiovascular effects of proteasome inhibitors and potential cardioprotective strategies.

\section{Discussion}

As opposed to other substance classes such as anthracyclines, proteasome inhibitors show distinct non-hematologic side effects. Bortezomib is mainly associated with mostly reversible neuropathy, ixazomib with gastrointestinal side effects, and carfilzomib with cardiotoxicity. Bortezomibinduced neurotoxicity is most likely non-proteasome mediated (51). This seems plausible, as carfilzomib is a more potent proteasome inhibitor and does not show similar neurotoxicity. Although cardiotoxicity has been shown for both bortezomib and carfilzomib in preclinical data, clinical data did not reveal a significant increase of cardiovascular adverse events in patients treated with bortezomib or ixazomib, while carfilzomib use led to an increase in cardiac biomarkers and heart failure.

The proteasome regulates protein quantity and quality control in maintaining health and preventing heart disease. Given that proper protein turnover is required for cardiac homeostasis and impaired proteasomal function contributes to heart disease, the contribution of proteasome inhibition to cardiac dysfunction is plausible. Preclinical studies have elucidated the underlying cardiac pathomechanisms of irreversible proteasome inhibition by carfilzomib. However, the molecular mechanisms are not yet fully understood, and only few cardioprotective strategies have been tested in preclinical studies and practically none in clinical studies. Few case series have been published indicating that medication withdrawal or dose reduction and heart failure medication might reverse cardiomyopathy in some cases $(23,52,53)$. Some of them report resolved cardiac dysfunction without discontinuation of carfilzomib (53). These findings have to be systematically confirmed in clinical studies. Meanwhile, cardiovascular toxicity under carfilzomib therapy could be addressed by reducing the dose, changing to bortezomib or ixazomib based regimens, and treating the cardiovascular side effects according to 
Table 2 Selected preclinical studies investigating the cardiovascular mechanisms related to protein inhibitors

\begin{tabular}{|c|c|c|c|c|c|c|}
\hline $\begin{array}{l}\text { Proteasome } \\
\text { inhibitor }\end{array}$ & Model & Dose used & Proposed pathomechanism & $\begin{array}{l}\text { Cardioprotective drug } \\
\text { or rationale }\end{array}$ & $\begin{array}{l}\text { Treatment } \\
\text { effect }\end{array}$ & Ref. \\
\hline Bortezomib & Wistar rat & $0.2 \mathrm{mg} / \mathrm{kg}$ BW $3 \times /$ week & $\begin{array}{l}\text { Mitochondrial dysfunction } \\
\text { leads to decrease in ATP } \\
\text { synthesis, disturbed } \mathrm{Ca}^{2+} \\
\text { handling, and ultimately } \\
\text { cardiac dysfunction }\end{array}$ & N/A & $\mathrm{N} / \mathrm{A}$ & (43) \\
\hline Carfilzomib & Wistar rat & $6 \times 4 \mathrm{mg} / \mathrm{kg}$ BW per day & $\begin{array}{l}\text { Activation of NF- } \mathrm{kB} \text { leads to } \\
\text { increase hypertrophic gene } \\
\text { expression, oxidative stress, } \\
\text { and apoptosis }\end{array}$ & $\begin{array}{l}\text { Rutin } 16 \times 20-40 \mathrm{mg} / \mathrm{kg} \\
\text { BW per day }\end{array}$ & $\begin{array}{l}\text { Reduced } \\
\text { toxicity }\end{array}$ & (45) \\
\hline Carfilzomib & Wistar rat & $6 \times 4 \mathrm{mg} / \mathrm{kg} \mathrm{BW}$ per day & $\begin{array}{l}\text { Increase in ROS leads to } \\
\text { myocardial damage }\end{array}$ & $\begin{array}{l}\text { Dexrazoxane } \\
16 \times 20-40 \mathrm{mg} / \mathrm{kg} \mathrm{BW} \\
\text { per day }\end{array}$ & $\begin{array}{l}\text { Reduced } \\
\text { toxicity }\end{array}$ & (47) \\
\hline Carfilzomib & $\begin{array}{l}\text { Rabbit } \\
\text { (ex vivo heart + } \\
\text { aorta) }\end{array}$ & $10^{-9}$ to $10^{-7} \mathrm{~mol} / \mathrm{L}$ & $\begin{array}{l}\text { Endothelial dysfunction leads } \\
\text { to vasospasms and reduced } \\
\text { sensitivity to nitroglycerin and } \\
\text { nifedipine }\end{array}$ & $\begin{array}{l}\text { Nitroglycerin and } \\
\text { nifedipine }\end{array}$ & $\begin{array}{l}\text { Partial } \\
\text { reversal of } \\
\text { vasospasms }\end{array}$ & (39) \\
\hline Carfilzomib & $\begin{array}{l}\text { Sprague- } \\
\text { Dawley rats } \\
\text { (PAH models) }\end{array}$ & $\begin{array}{l}4 \times 6 \mathrm{mg} / \mathrm{kg} \mathrm{BW} \text { in } \\
2 \text { weeks }\end{array}$ & $\begin{array}{l}\text { Increase in ubiquitylation of } \\
\text { major vault and heat shock } \\
\text { proteins lead to apoptosis in } \\
\text { the left ventricle }\end{array}$ & $\begin{array}{l}\text { Dexrazoxane/ } \\
\text { pifithrin- } \alpha\end{array}$ & $\begin{array}{l}\text { Reduced left } \\
\text { ventricular } \\
\text { apoptosis }\end{array}$ & (42) \\
\hline MG262 & $\begin{array}{l}\text { Mice carrying } \\
\text { NFAT binding } \\
\text { site-dependent } \\
\text { luciferase } \\
\text { reporter }\end{array}$ & $5 \mu \mathrm{mol} / \mathrm{kg} \mathrm{BW}$ & $\begin{array}{l}\text { Activation of NFAT-calcineurin } \\
\text { pathway }\end{array}$ & N/A & N/A & (48) \\
\hline MLN-273 & Domestic pigs & $0.08 \mathrm{mg} / \mathrm{kg}$ BW per day & $\begin{array}{l}\text { Vascular dysfunction, myocyte } \\
\text { hypertrophy, increase in } \\
\text { apoptosis, and perivascular } \\
\text { and interstitial fibrosis lead to } \\
\text { hypertrophic cardiomyopathy } \\
\text { with diastolic dysfunction }\end{array}$ & $\mathrm{N} / \mathrm{A}$ & N/A & (38) \\
\hline
\end{tabular}

$\mathrm{PAH}$, pulmonary arterial hypertension; BW, body weight; ROS, reactive oxygen species; N/A, not available. 
current guidelines $(54,55)$.

So far, there is no risk stratification available. Baseline echocardiography, cardiovascular risk factors, and biomarkers are not conclusive when assessing the individual risk for cardiotoxicity (20,21). Monitoring cardiac function as well as close interdisciplinary collaboration between cardiologist and oncologist is essential to provide optimal medical care for these patients (54).

\section{Acknowledgements}

None.

\section{Footnote}

Conflicts of Interest: The authors have no conflicts of interest to declare.

\section{References}

1. Cowan AJ, Allen C, Barac A, et al. Global Burden of Multiple Myeloma: A Systematic Analysis for the Global Burden of Disease Study 2016. JAMA Oncol 2018;4:1221-7.

2. De Stefano V, Za T, Rossi E. Venous thromboembolism in multiple myeloma. Semin Thromb Hemost 2014;40:338-47.

3. Gavriatopoulou M, Musto P, Caers J, et al. European myeloma network recommendations on diagnosis and management of patients with rare plasma cell dyscrasias. Leukemia 2018;32:1883-98.

4. Cornell RF, Kassim AA. Evolving paradigms in the treatment of relapsed/refractory multiple myeloma: increased options and increased complexity. Bone Marrow Transplant 2016;51:479-91.

5. Richardson PG, Barlogie B, Berenson J, et al. A Phase 2 Study of Bortezomib in Relapsed, Refractory Myeloma. N Engl J Med 2003;348:2609-17.

6. Richardson PG, Sonneveld P, Schuster MW, et al. Bortezomib or High-Dose Dexamethasone for Relapsed Multiple Myeloma. N Engl J Med 2005;352:2487-98.

7. Richardson PG, Sonneveld P, Schuster MW, et al. Reversibility of symptomatic peripheral neuropathy with bortezomib in the phase III APEX trial in relapsed multiple myeloma: impact of a dose-modification guideline. Br J Haematol 2009;144:895-903.

8. Stewart AK, Rajkumar SV, Dimopoulos MA, et al. Carfilzomib, lenalidomide, and dexamethasone for relapsed multiple myeloma. $\mathrm{N}$ Engl J Med 2015;372:142-52.

9. Dimopoulos MA, Moreau P, Palumbo A, et al. Carfilzomib and dexamethasone versus bortezomib and dexamethasone for patients with relapsed or refractory multiple myeloma (ENDEAVOR): a randomised, phase 3, open-label, multicentre study. Lancet Oncol 2016;17:27-38.

10. Garderet L, Iacobelli S, Moreau P, et al. Superiority of the triple combination of bortezomib-thalidomidedexamethasone over the dual combination of thalidomidedexamethasone in patients with multiple myeloma progressing or relapsing after autologous transplantation: the MMVAR/IFM 2005-04 Randomized Phase III Trial from the Chronic Leukemia Working Party of the European Group for Blood and Marrow Transplantation. J Clin Oncol 2012;30:2475-82.

11. Sonneveld P, Schmidt-Wolf IGH, van der Holt B, et al. Bortezomib Induction and Maintenance Treatment in Patients With Newly Diagnosed Multiple Myeloma: Results of the Randomized Phase III HOVON-65/ GMMG-HD4 Trial. J Clin Oncol 2012;30:2946-55.

12. Richardson PG, Xie W, Jagannath $S$, et al. A phase 2 trial of lenalidomide, bortezomib, and dexamethasone in patients with relapsed and relapsed/refractory myeloma. Blood 2014;123:1461-9.

13. Badros AZ, Vij R, Martin T, et al. Carfilzomib in multiple myeloma patients with renal impairment: pharmacokinetics and safety. Leukemia 2013;27:1707-14.

14. Hájek R, Masszi T, Petrucci MT, et al. A randomized phase III study of carfilzomib vs low-dose corticosteroids with optional cyclophosphamide in relapsed and refractory multiple myeloma (FOCUS). Leukemia 2017;31:107-14.

15. Moreau P, Masszi T, Grzasko N, et al. Oral Ixazomib, Lenalidomide, and Dexamethasone for Multiple Myeloma. N Engl J Med 2016;374:1621-34.

16. Infante JR, Mendelson DS, Burris HA, et al. A firstin-human dose-escalation study of the oral proteasome inhibitor oprozomib in patients with advanced solid tumors. Invest New Drugs 2016;34:216-24.

17. Vogl DT, Martin TG, Vij R, et al. Phase I/II study of the novel proteasome inhibitor delanzomib (CEP-18770) for relapsed and refractory multiple myeloma. Leuk Lymphoma 2017;58:1872-9.

18. Spencer A, Harrison S, Zonder J, et al. A phase 1 clinical trial evaluating marizomib, pomalidomide and lowdose dexamethasone in relapsed and refractory multiple myeloma (NPI-0052-107): final study results. Br J Haematol 2018;180:41-51. 
19. Siegel D, Martin T, Nooka A, et al. Integrated safety profile of single-agent carfilzomib: experience from 526 patients enrolled in 4 phase II clinical studies. Haematologica 2013;98:1753-61.

20. Chen JH, Lenihan DJ, Phillips SE, et al. Cardiac events during treatment with proteasome inhibitor therapy for multiple myeloma. Cardio-Oncology 2017;3:4.

21. Rosenthal A, Luthi J, Belohlavek M, et al. Carfilzomib and the cardiorenal system in myeloma: an endothelial effect? Blood Cancer J 2016;6:e384.

22. Danhof S, Schreder M, Rasche L, et al. 'Real-life' experience of preapproval carfilzomib-based therapy in myeloma - analysis of cardiac toxicity and predisposing factors. Eur J Haematol 2016;97:25-32.

23. Dimopoulos MA, Roussou M, Gavriatopoulou M, et al. Cardiac and renal complications of carfilzomib in patients with multiple myeloma. Blood Adv 2017;1:449-54.

24. Gavazzoni M, Vizzardi E, Gorga E, et al. Mechanism of cardiovascular toxicity by proteasome inhibitors: New paradigm derived from clinical and pre-clinical evidence. Eur J Pharmacol 2018;828:80-8.

25. Brooks P, Fuertes G, Murray RZ, et al. Subcellular localization of proteasomes and their regulatory complexes in mammalian cells. Biochem J 2000;346 Pt 1:155-61.

26. Gomes A V, Zong C, Edmondson RD, et al. Mapping the murine cardiac $26 \mathrm{~S}$ proteasome complexes. Circ Res 2006;99:362-71.

27. Cui Z, Scruggs SB, Gilda JE, et al. Regulation of cardiac proteasomes by ubiquitination, SUMOylation, and beyond. J Mol Cell Cardiol 2014;71:32-42.

28. Schubert U, Antón LC, Gibbs J, et al. Rapid degradation of a large fraction of newly synthesized proteins by proteasomes. Nature 2000;404:770-4.

29. Xu G, Paige JS, Jaffrey SR. Global analysis of lysine ubiquitination by ubiquitin remnant immunoaffinity profiling. Nat Biotechnol 2010;28:868-73.

30. Wang X, Li J, Zheng H, et al. Proteasome functional insufficiency in cardiac pathogenesis. Am J Physiol Heart Circ Physiol 2011;301:H2207-19.

31. Willis MS, Townley-Tilson WHD, Kang EY, et al. Sent to destroy: the ubiquitin proteasome system regulates cell signaling and protein quality control in cardiovascular development and disease. Circ Res 2010;106:463-78.

32. Su H, Wang X. The ubiquitin-proteasome system in cardiac proteinopathy: a quality control perspective. Cardiovasc Res 2010;85:253-62.

33. Day SM. The ubiquitin proteasome system in human cardiomyopathies and heart failure. Am J Physiol Heart
Circ Physiol 2013;304:H1283-93.

34. Predmore JM, Wang P, Davis F, et al. Ubiquitin Proteasome Dysfunction in Human Hypertrophic and Dilated Cardiomyopathies. Circulation 2010;121:997-1004.

35. Patel MB, Majetschak M. Distribution and interrelationship of ubiquitin proteasome pathway component activities and ubiquitin pools in various porcine tissues. Physiol Res 2007;56:341-50.

36. Ettari R, Zappalà M, Grasso S, et al. Immunoproteasomeselective and non-selective inhibitors: A promising approach for the treatment of multiple myeloma. Pharmacol Ther 2018;182:176-92.

37. Demo SD, Kirk CJ, Aujay MA, et al. Antitumor activity of PR-171, a novel irreversible inhibitor of the proteasome. Cancer Res 2007;67:6383-91.

38. Herrmann J, Wohlert C, Saguner AM, et al. Primary proteasome inhibition results in cardiac dysfunction. Eur J Heart Fail 2013;15:614-23.

39. Chen-Scarabelli C, Corsetti G, Pasini E, et al. Spasmogenic Effects of the Proteasome Inhibitor Carfilzomib on Coronary Resistance, Vascular Tone and Reactivity. EBioMedicine 2017;21:206-12.

40. Nayak L, Shi H, Atkins GB, et al. The thromboprotective effect of bortezomib is dependent on the transcription factor Kruppel-like factor 2 (KLF2). Blood 2014;123:3828-31.

41. Komander D. The emerging complexity of protein ubiquitination. Biochem Soc Trans 2009;37:937-53.

42. Wang X, Ibrahim YF, Das D, et al. Carfilzomib reverses pulmonary arterial hypertension. Cardiovasc Res 2016;110:188-99.

43. Nowis D, Maczewski M, Mackiewicz U, et al. Cardiotoxicity of the anticancer therapeutic agent bortezomib. Am J Pathol 2010;176:2658-68.

44. Meiners S, Dreger H, Fechner M, et al. Suppression of cardiomyocyte hypertrophy by inhibition of the ubiquitinproteasome system. Hypertension 2008;51:302-8.

45. Imam F, Al-Harbi NO, Al-Harbia MM, et al. Rutin Attenuates Carfilzomib-Induced Cardiotoxicity Through

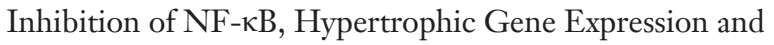
Oxidative Stress. Cardiovasc Toxicol 2017;17:58-66.

46. Imam F, Al-Harbi NO, Al-Harbi MM, et al. Apremilast reversed carfilzomib-induced cardiotoxicity through inhibition of oxidative stress, NF- $\kappa \mathrm{B}$ and MAPK signaling in rats. Toxicol Mech Methods 2016;26:700-8.

47. Al-Harbi NO. Carfilzomib-induced cardiotoxicity mitigated by dexrazoxane through inhibition of hypertrophic gene expression and oxidative stress in rats. 
Toxicol Mech Methods 2016;26:189-95.

48. Tang M, Li J, Huang W, et al. Proteasome functional insufficiency activates the calcineurin-NFAT pathway in cardiomyocytes and promotes maladaptive remodelling of stressed mouse hearts. Cardiovasc Res 2010;88:424-33.

49. Spur EM, Althof N, Respondek D, et al. Inhibition of chymotryptic-like standard proteasome activity exacerbates doxorubicin-induced cytotoxicity in primary cardiomyocytes. Toxicology 2016;353-354:34-47.

50. Zhang C, Jiang H, Wang $\mathrm{P}$, et al. Transcription factor NF-kappa B represses ANT1 transcription and leads to mitochondrial dysfunctions. Sci Rep 2017;7:44708.

51. Arastu-Kapur S, Anderl JL, Kraus M, et al. Nonproteasomal Targets of the Proteasome Inhibitors Bortezomib and Carfilzomib: a Link to Clinical Adverse Events. Clin Cancer Res 2011;17:2734-43.

52. Chari A, Hajje D. Case series discussion of cardiac and vascular events following carfilzomib treatment: possible

Cite this article as: Heckmann MB, Doroudgar S, Katus HA, Lehmann LH. Cardiovascular adverse events in multiple myeloma patients. J Thorac Dis 2018;10(Suppl 35):S4296S4305. doi: $10.21037 /$ jtd.2018.09.87 mechanism, screening, and monitoring. BMC Cancer 2014;14:915.

53. Jain T, Narayanasamy H, Mikhael J, et al. Systolic dysfunction associated with carfilzomib use in patients with multiple myeloma. Blood Cancer J 2017;7:642.

54. Zamorano JL, Lancellotti P, Rodriguez Muñoz D, et al. 2016 ESC Position Paper on cancer treatments and cardiovascular toxicity developed under the auspices of the ESC Committee for Practice Guidelines. Eur Heart J 2016;37:2768-801.

55. Ponikowski P, Voors AA, Anker SD, et al. 2016 ESC Guidelines for the diagnosis and treatment of acute and chronic heart failure: The Task Force for the diagnosis and treatment of acute and chronic heart failure of the European Society of Cardiology (ESC)Developed with the special contribution of the Heart Failure Association (HFA) of the ESC. Eur Heart J 2016;37:2129-200. 